\title{
Erratum zu: Mit den Augen der Psychoanalyse
}

Der Blick in das Verborgene

\section{Otmar Seidl}

Online publiziert: 6. April 2021

(C) Springer Medizin Verlag GmbH, ein Teil von Springer Nature 2021

\section{Erratum zu:}

\section{Forum Psychoanal 2020}

https://doi.org/10.1007/s00451-020-00418-1

Der Originalartikel enthielt leider einen Fehler.

Unter der Überschrift „Vignette 3“, gegen Ende des ersten Abschnitts muss der Satz folgendermaßen lauten: ... Er erschrak über diesen Einfall, weil er an den Stier des Phalaris denken musste, der seine Opfer in den glühenden Bauch eines erzenen Stieres gesteckt hatte, um sich dann an dem Brüllen der Eingeschlossenen zu ergötzen.

Der Originalartikel wurde korrigiert.

Die Online-Version des Originalartikels ist unter https://doi.org/10.1007/s00451-020-00418-1 zu finden.

Dr. med. O. Seidl

Klinik und Poliklinik für Psychiatrie und Psychotherapie, Sektion für Psychosomatische Medizin und Psychotherapie, LMU Klinikum München, München, Deutschland

Konitzerstr. 12, 81927 München, Deutschland

E-Mail: o.seidl@hotmail.de 